\title{
Coronary artery surgery using inverted internal mammary artery
}

\author{
J J GOITI, G H SMITH
}

From the Cardiothoracic Unit, Northern General Hospital, Sheffield

SUMMARY A 56-year-old man requiring multiple coronary artery bypass grafts but without enough suitable vein was operated upon using the retrograde flow of the right internal mammary artery to supply the posterior descending coronary artery.

Relief of angina and non-ischaemic areas on the scan with thallium-201 supports our intention to use this method when other techniques are not possible.

Coronary artery bypass using autologous venous grafts is established in the treatment of angina pectoris. Daunting technical problems are encountered when no suitable veins are available.

The purpose of reporting this case is to present the clinical use of retrograde internal mammary artery grafting to overcome this problem.

\section{Case report}

A 56-year-old journalist was known to suffer with mild diabetes mellitus and to have Fredrickson type IV hyperlipidaemia. He had two previous myocardial infarctions. He complained of severe angina unresponsive to conventional medical treatment. In the past he had suffered with varicose veins in both legs and had had deep venous thromboses. In addition, the veins in the arms had been damaged by multiple injections and infusions during the treatment of diabetic complications.

Coronary arteriography showed a $90 \%$ stenosis of the left anterior descending coronary artery, involving the origin of the first diagonal coronary artery, $70 \%$ stenosis at the origin of the obtuse marginal artery, and total occlusion of the right coronary artery in its middle third. The distal right coronary artery filled retrogradely from the left-sided injection.

Surgery was performed on 30 March 1981 . In spite of multiple explorations, only enough vein for one graft, of about $12 \mathrm{~cm}$, could be found. After median sternotomy, both internal mammary arteries were mobilised from the second to the seventh costal cartilage. The left-sided artery was divided at the level of the diaphragm and excellent anterograde flow was obtained. The right internal mammary artery was divided at the level of the second costal cartilage and a retrograde flow of approximately $40 \mathrm{ml} / \mathrm{min}$ was obtained.

After cardiopulmonary bypass was established, cold cardioplegic solution arrested the heart. The vein was sewn to the opened obtuse marginal artery which

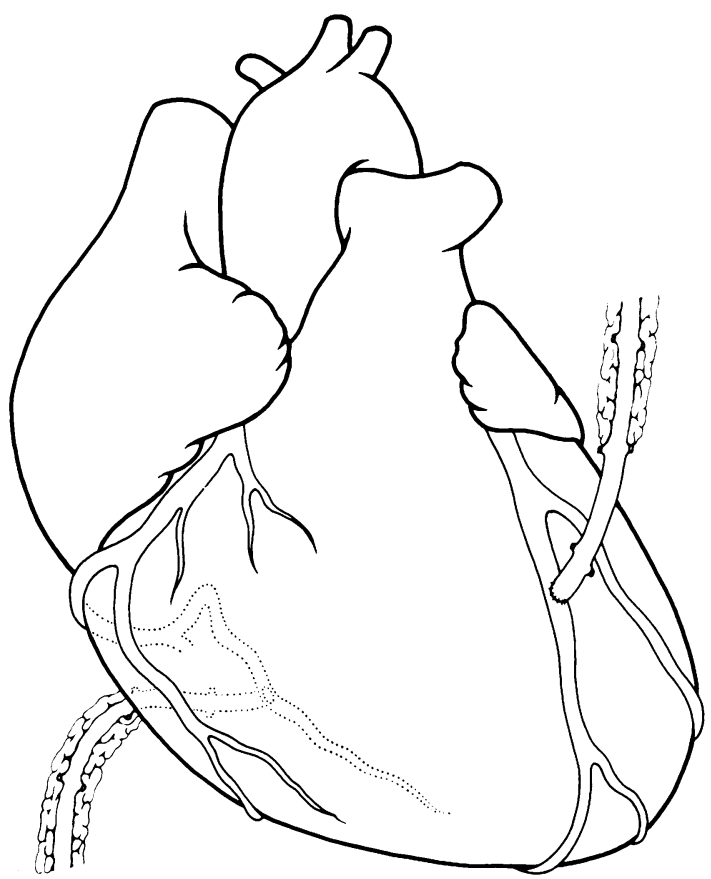

Fig. Left internal mammary artery anastomosed to the left anterior descending coronary artery. Retrograde right internal mammary artery anastomosed to posterior descending coronary artery. Vein graft to the obtuse marginal and first diagonal are not shown.

81 
had a lumen of $2 \mathrm{~mm}$ and a side to side anastomosis was performed to the first diagonal artery which had a lumen of $1.5 \mathrm{~mm}$. The left internal mammary artery was anastomosed to the left anterior descending coronary artery $(2 \mathrm{~mm})$ and the retrograde right internal mammary to the posterior descending coronary artery $(2 \mathrm{~mm})$. The venous anastomoses were performed using 6/0 Prolene and the mammary arterial anastomoses with 7/0 Prolene.

Spontaneous defibrillation occurred on removal of the aortic clamp at 50 minutes. The vein was attached to the ascending aorta.

The period after bypass and after the operative period was uneventful. Examination of the electrocardiogram and serum enzymes showed no evidence of myocardial damage.

Eighteen days after operation the patient had myocardial imaging using thallium-201. Exercise to exhaustion did not cause angina. The scan showed a defect of distribution without later correction in the lateral wall of the left ventricle only, suggesting lateral myocardial infarction, compatible with the history before operation. Angiography showed excellent patency of the left internal mammary artery graft, but occlusion of the venous graft. Repeated attempts to inject the right internal mammary artery via the epigastric route failed.

The patient continues to be free of pain and is leading a very active life eight months after operation.

\section{Discussion}

Our experience with artificial substitutes for coronary artery bypass graft in the absence of autologous vein has been far from satisfactory. This patient who required four coronary artery bypass grafts forced us to adopt the above manoeuvre, having read the experimental results of Folts et al. ${ }^{1}$ using retrograde internal mammary artery flow for revascularisation of coronary arteries. We believe this is the first clinical use of this method.

The patency rate of internal mammary arteries is higher than autologous vein grafts, but only with anterograde flow. ${ }^{2}$ Unfortunately, we have not been able to show the patency of the graft by angiography because of anatomical difficulties, but the thallium scan suggests good myocardial perfusion in the area perfused by the retrograde right internal mammary artery graft. In addition, angiography after operation did not show retrograde filling of the right coronary artery, as happened before operation, though of course this could be the result of operative damage to the artery. The total relief of the angina in this patient supports the idea of using this new technique in cases requiring multiple coronary artery bypass grafts when other techniques are inappropriate.

\section{References}

1 Folts JD, Gallagher KP, Kroncke GM, Rowe GG. Myocardial revascularization of the canine circumflex coronary artery using retrograde internal mammary artery flow without cardiopulmonary bypass. Ann Thorac Surg 1981; 31: 21-7.

2 Mathieu P, Giorgi C, Helmer J, Coepfert CH. Patency rate and functional results of left anterior descending bypass surgery by internal mammary artery. In: Poskamm H, Schmuziger M, eds. Coronary heart surgery. Berlin, Heidelberg, \& New York: Springer-Verlag, 1979: 112-9.

Requests for reprints to J J Goiti, Esq, Cardiothoracic Unit, Northern General Hospital, Sheffield S5 7AU. 